\title{
Technology Integration through Digital Learning Hub in Skill-Oriented Entrepreneurial Education
}

\author{
Rajdeep Deb $^{1}$, D K Bhatt ${ }^{1}$ \\ rajdeep.deb@ruj-bsdu.in, \\ devendrakumar.bhatt@ruj-bsdu.in
}

${ }^{1}$ School of Entrepreneurship Skills, BSDU, Jaipur, 302037, India

\begin{abstract}
The prime focus of most entrepreneurial education is to develop some level of entrepreneurial competencies and skill levels. This paper explores novel opportunities that Web 2.0 and 3.0 tools created for extending teacher-learner, learner-learner and teacherteacher communications, interactions and collaborations to infuse entrepreneurial competencies and skill level. The research findings also prove that interaction with these tools is expected to contribute to the development of cross-curricular generic competences. Implications for setting up of technology-based skill-oriented entrepreneurship education program are provided.
\end{abstract}

Keywords: Web 2.0 and 3.0 tools, Digital learners, Technology Integration, Digital learning hub, Semantic Web.

\section{Introduction}

Entrepreneurial Education (EE) has traditionally focused on conventional teaching to develop learners' "enterprising self", but in recent past, many initiatives are increasingly becoming more technology-based highlighting hands-on skill training and learning-by-doing model. Undoubtedly, 21st centuries learners will come to class expecting teachers to integrate the web communication tools to be used in day to day class affairs [1]. Being the 21 st century's teacher, it is our duty to meet these expectations, especially when you are a big believer in differentiation in teaching. As a teacher who advocates for technology integration, we need to be more industrious in teaching our learners in many different ways of learning today's technology and giving them the chance to explore more about using freely available Web 2.0 and 3.0 technology tools.

\section{Rajdeep Deb}

School of Entrepreneurship Skills, BSDU, Jaipur, 302037, India

rajdeep.deb@ruj-bsdu.in,

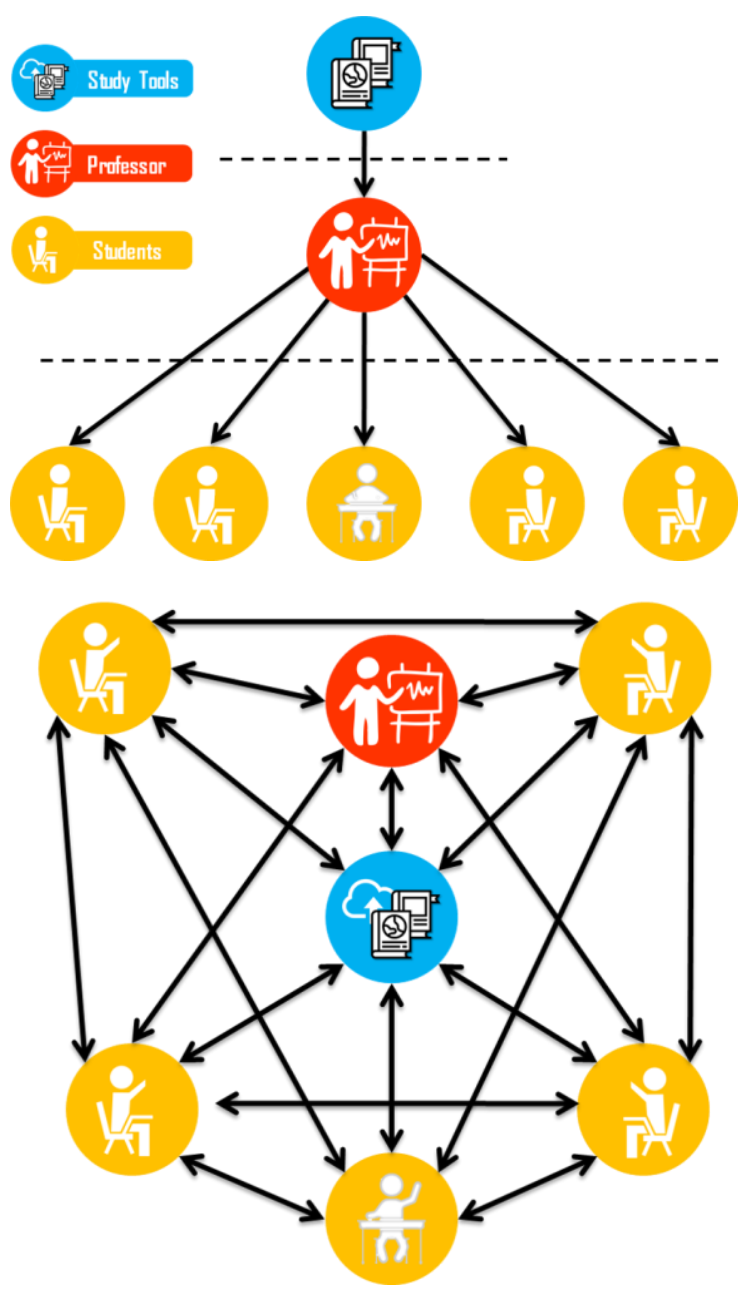

Figure 1: Digital model of learning, equip your learners beforehand.

Despite the fact that Web 2.0 and 3.0 tools nearly always involved in facilitating the learning of the learner, choosing the right tools to teach always remains a challenge for teachers $[2,3]$. The teachers are using most of these tools but do not recognize them as Web 2.0 and 3.0 tools. Examples are Facebook, email, blog, wiki, map, YouTube, Wolfram Alpha ...etc. [4-7]. When it comes to the integration of these Web 2.0 and 3.0 tools to facilitate or meet the learning expectations of the learner, the situation is very forbidding [8-10]. 
Table1: The history of web tools present three major stages:

\begin{tabular}{|c|c|c|c|l|}
\hline Generation & $\begin{array}{c}\text { Institute/Educat } \\
\text { or }\end{array}$ & Learners & $\begin{array}{c}\text { Device } \\
\text { Independent }\end{array}$ & \multicolumn{1}{|c|}{ Outcome } \\
\hline Web 1.0 & P & C & - & Democratization of Information access \\
\hline Web 2.0 & P C & P C & - & Democratization of Content Production \\
\hline Web 3.0 & P C & P C & P C & Democratization of the capacity of action and knowledge \\
\hline
\end{tabular}

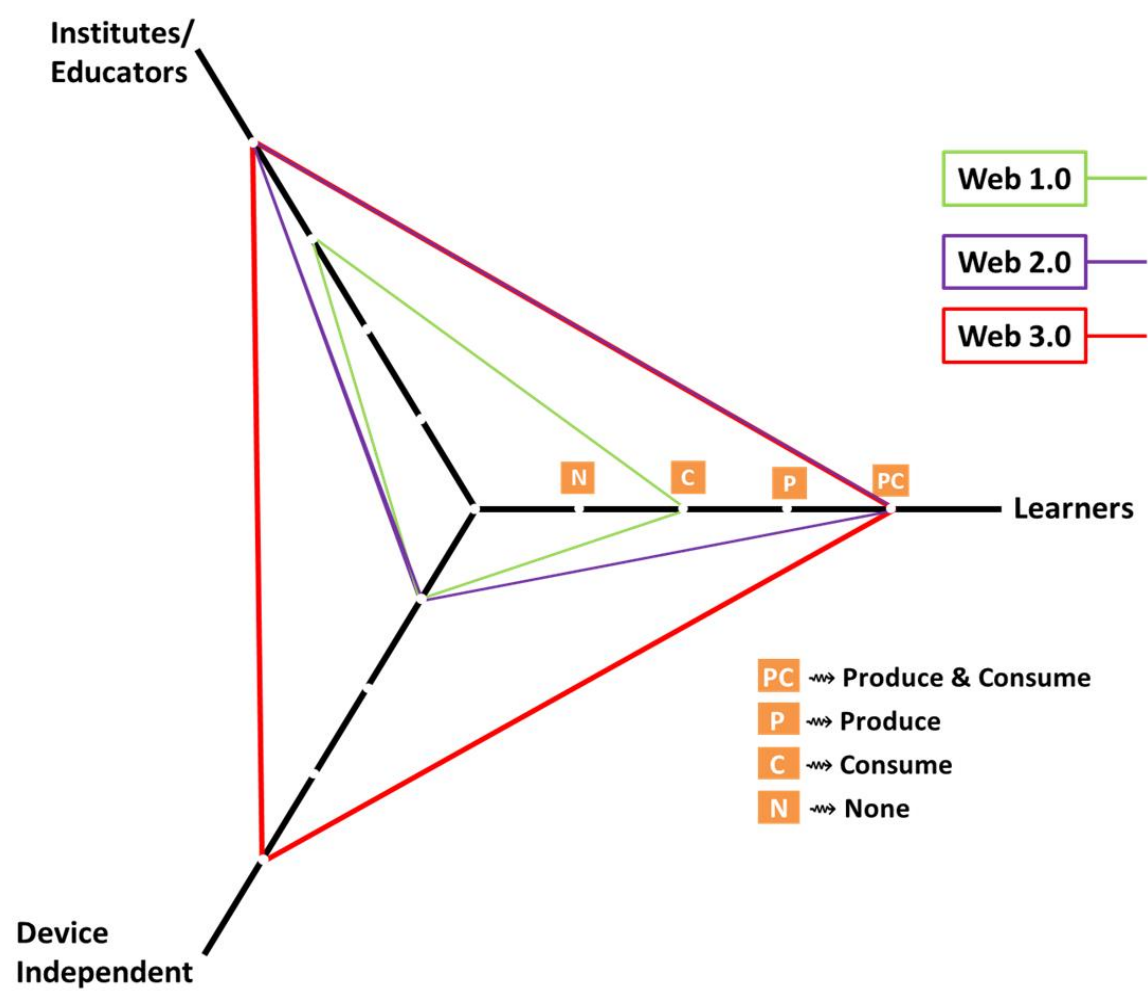

Figure 2: Spider chart showing the distribution of web tool generation

This article focuses on designing and developing a Digital Learning Hub to facilitate entrepreneurial competencies and skill levels using freely available web 2.0 and 3.0 tools.

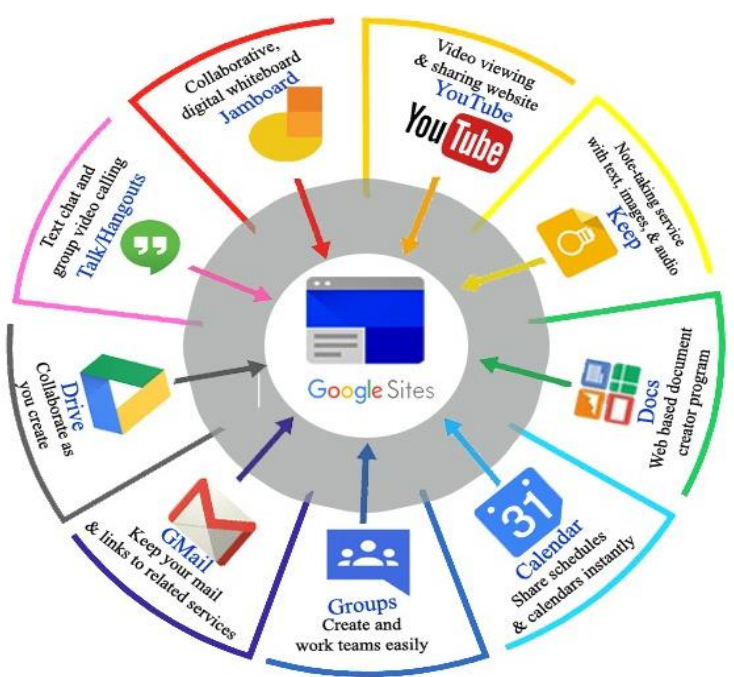

Figure 3: Integration of Google product into Google Site.

Figure 3 depicts the integration of some of these freely available tools into Google sites to build a digital learning hub for an undergraduate level introductory entrepreneurial course. In the present study, we will make an appraisal of this digital learning hub to ensure entrepreneurial competencies and skill levels [11-12]. This article also through light on the different tools and techniques developed through this integration for the mutual benefit of teacher and learners, so that quality entrepreneurial education for everyone can be offered everywhere. Finally, we will discuss the timeframe required to develop such digital learning hub.

\section{Statement of Objectives:}

In most of the instructional strategies developed, learners' interactions with each other are a neglected aspect of instructions. The majority of them are designed around to help teachers to maintain optimum interaction between learners and study resource/tools. Some of the strategies talked about teacher's interaction with the learners but almost in all strategies, the interaction between the learners is relatively ignored. So here an approach was taken to develop a digital learning hub based on freely available Web 2.0 and 3.0 tools to facilitate learnerlearner interactions along with the learner-resource and learner-teacher interactions.

The tricky part about all these Web 2.0 and 3.0 tools is, how to find the suitable one for our learners' requirements? In this article, we tried to divide it into 
different parts depending on the requirement of the teacher and learner and give appropriate examples of how it could be used to enhance learners learning. Effective integration of technology is achieved when teachers able to select technology tools to help them obtain information in a timely manner, analyze and synthesize the information, and present it professionally. This paper presents the first of its kind study on integration Web 2.0 and 3.0 tools for enriching the learning experience of undergraduate level learners with introductory level entrepreneurial courses as a medium. Recommendations were made for integrating selected freely available Web 2.0 and 3.0 tools in major instructional and content areas.

\section{Results and Discussion}

All along with the evolution of globalization and digital technologies, educators have touted the benefits of learning with technology-based educational tools such as spreadsheets, videos, and databases that allow learners to actively process and manipulate information. In today's world, it is paramount that we should give our learners' skills like ideation, innovation, digital and virtual global collaboration, design thinking, adaptive thinking, etc. In one word, we need to give our learners an Entrepreneurial Mindset, an umbrella term that covers all of these skills naturally and effectively. Without the integration of technology, it is near impossible to ensure these skill competencies effectively. Hundreds of Web 2.0 and 3.0 tools are available for making the technology as tool to enrich the learning of our digital learners. Inspired by these in the present work we build a digital learning hub for an undergraduate level introductory entrepreneurial course by integrating some of the freely available Web 2.0 and 3.0 tools. Choice of the tools primarily based on their accessibility to the users at free of cost.

Today's teachers need to be aware of the fact that learners in most of the cases will be more techs savvy than the teachers because they are digital native. Now it is the turn of the teacher to learn and harness these capabilities to engage learners and promote active learning. The prime purpose of this digital learning hub is to give all the learning content of the course to their fingertips through their handheld devices. Each tab in this digital learning hub acts as an online collaborative interface for ideating, creating, innovating, sharing, tracking, documenting, reporting and delivery of electronic content to the learners and above all to enrich their learning experience. Few of the study tools developed and integrated into the digital learning hub are detailed below.

Ideation Board: Ideation refers to the process of creating, developing and communicating prescriptive ideas with others, typically in a business setting. The process of ideation is the stepping stone of any innovation and a quite essential part of entrepreneurial education. A tool to facilitate ideation process among learners was developed by integrating Google Jamboard and Keep with Google sites.

Business Model Canvas (BMC): By integrating Google sheet with Google drive features, a virtual BMC tool was developed. A short description with some dropdown examples was provided that help the learner to develop his/her first BMC effortlessly. The best benefit of the virtual BMC tool is that it acts as a physical sticky note so that the learner can do any change or modification as and when they need it. They can use different colors for different value propositions and customer groups. Also, they can create many different versions and save it in drive.

Market Research Tool: Market research is an essential element in improving, evolving and truly crafting any products and services for entrepreneurial ventures. Most of these tools in this category are in the freemium category. Here we integrated freely available Google services like keyword search, and trend in our digital learning hub, to develop the market research tool for our learner which at per with any premium service.

In addition to the technological tools that facilitate entrepreneurial interaction among the stakeholders, we also developed and integrated few more technology tools that every teacher would love to have in their back yard to facilitate and enrich the learning of their learner.

Academic calendar: It supplements learners all academic endeavors with relevant dates and schedules for different academic activity all through the semester. This was provided to the learners by integrating Picasa web album with Google slideshow.

Announcement page: An announcement page with a countdown timer was developed so that it will display the latest announcements with countdown timer in it. This plugin is best suitable for highlighting the deadline for different academic activities.

All other study tools developed for this digital learning hub with the associated Web 2.0 and 3.0 tools are tabulated in Table 2.

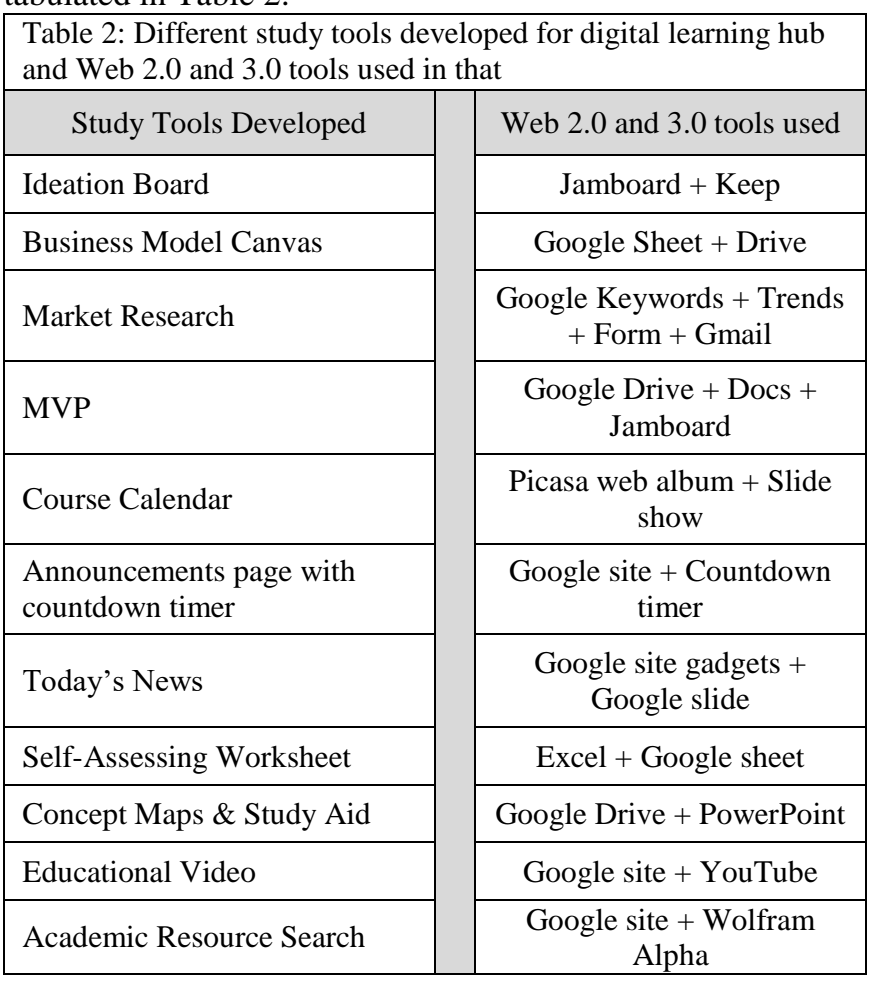

Table 3 distribution of different Web 2.0 and 3.0 tools and their application in different aspects of the interaction as well as instructional area, is shown. What most important in this table is the reflection of how these tools were used to serve the need of digital learners. It was an eye-opener for us to see that some learners after completing their mandatory assigned work spent additional time to 
improve upon their work as these tools empower them to do so.

\begin{tabular}{|c|c|c|c|c|c|c|c|c|c|c|}
\hline \multirow{2}{*}{\multicolumn{2}{|c|}{ Web 2.0 and 3.0 tools }} & \multicolumn{9}{|c|}{ Different Instructional Areas and Associated Tools } \\
\hline & & \multirow[t]{2}{*}{$\begin{array}{c}\text { Ideation } \\
\text { Board }\end{array}$} & \multirow{2}{*}{$\begin{array}{c}\begin{array}{c}\text { Business } \\
\text { Model } \\
\text { Canvas }\end{array} \\
\boldsymbol{V}\end{array}$} & \multirow[t]{2}{*}{$\begin{array}{l}\text { Market } \\
\text { Research }\end{array}$} & \multirow{2}{*}{$\frac{\text { MVP }}{\sqrt{ }}$} & \multirow{2}{*}{$\begin{array}{c}\begin{array}{c}\text { Sharing } \\
\text { study } \\
\text { material }\end{array} \\
\sqrt{ }\end{array}$} & \multirow{2}{*}{ 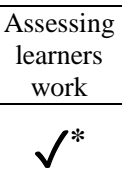 } & \multirow[t]{2}{*}{$\begin{array}{l}\text { Real-time } \\
\text { interaction }\end{array}$} & \multirow[t]{2}{*}{$\begin{array}{c}\text { Pre/Post } \\
\text { class } \\
\text { discussion }\end{array}$} & \multirow[t]{2}{*}{$\begin{array}{c}\text { Academic } \\
\text { deadlines } \\
\text { notification }\end{array}$} \\
\hline & Drive & & & & & & & & & \\
\hline$\frac{M}{\underline{\underline{\underline{E}}}}$ & Docs & & $\sqrt{ }$ & $\sqrt{ }^{\#}$ & $\sqrt{ }$ & $\sqrt{ }$ & $\boldsymbol{V}^{*}$ & & & \\
\hline $\begin{array}{l}\text { You } \\
\text { Tube }\end{array}$ & YouTube & & & & & $\sqrt{ }$ & & & & \\
\hline 31 & Calendar & & & & & & & & & $\sqrt{ }^{\$}$ \\
\hline عـ & Groups & & & & & & & & $\sqrt{ }$ & \\
\hline & Hangout & & & & & & & $\sqrt{ }$ & $\sqrt{ }$ & \\
\hline & Gmail & & & $\sqrt{ }^{\#}$ & & & & & $\sqrt{ }$ & $\searrow^{\$}$ \\
\hline E & Keep & $\sqrt{ }$ & & & & & & & & \\
\hline & Jam Board & $\sqrt{ }$ & & & $\sqrt{ }$ & & & $\sqrt{ }$ & & \\
\hline & $\begin{array}{l}\text { \#: other too } \\
\text { \$: Other W } \\
\text { *: Other W }\end{array}$ & $\begin{array}{l}\text { ntegrated } \\
2.0 \text { and } 3 \text {. } \\
2.0 \text { and } 3 \text {. }\end{array}$ & $\begin{array}{l}\text { Google K } \\
\text { ls integra } \\
\text { Is integrat }\end{array}$ & $\begin{array}{l}\text { ords, Goog } \\
\text {.g. Picasa } \\
\text { g. differe }\end{array}$ & $\begin{array}{l}\text { rends in } \\
\text { album } \\
\text { d on wi }\end{array}$ & $\begin{array}{l}\text { ogle sites } \\
\text { Google sit } \\
\text { yoogle doc }\end{array}$ & & & & \\
\hline
\end{tabular}




\section{Integration Web 3.0 tools for better academic search:}

One of the Web 3.0 tools that we integrated with our digital learning hub and would like to specifically described in this paper is Wolfram Alpha. This Natural Language Understanding (NLU) System able to summarize large amounts of information into knowledge and useful actions for our learners. To demonstrate the fact a little comparison between Wolfram Alpha and Google Search, using both tools, typing the "Engineering and Technology" phrase in both search engines is shown in figure 4 , and then we see big differences in the results:

\section{WolframAlpha}

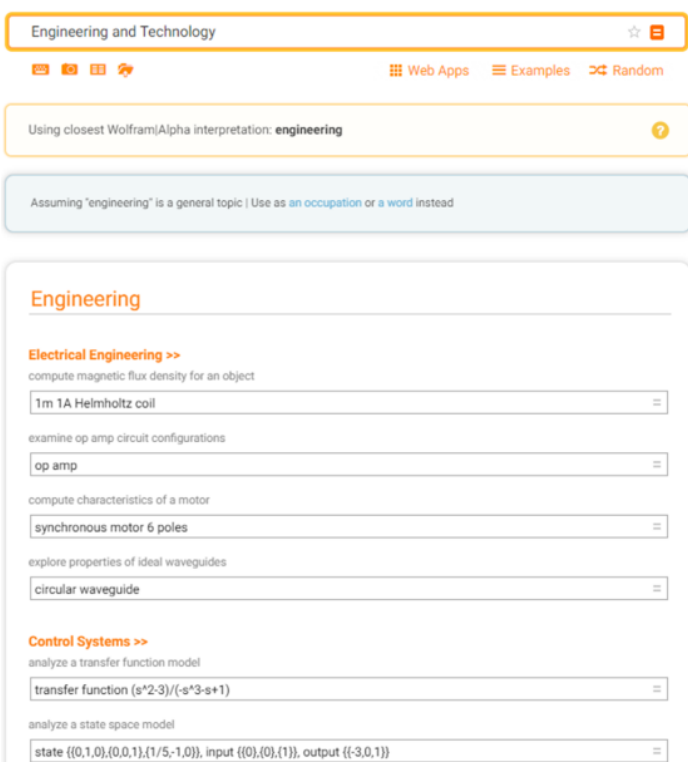

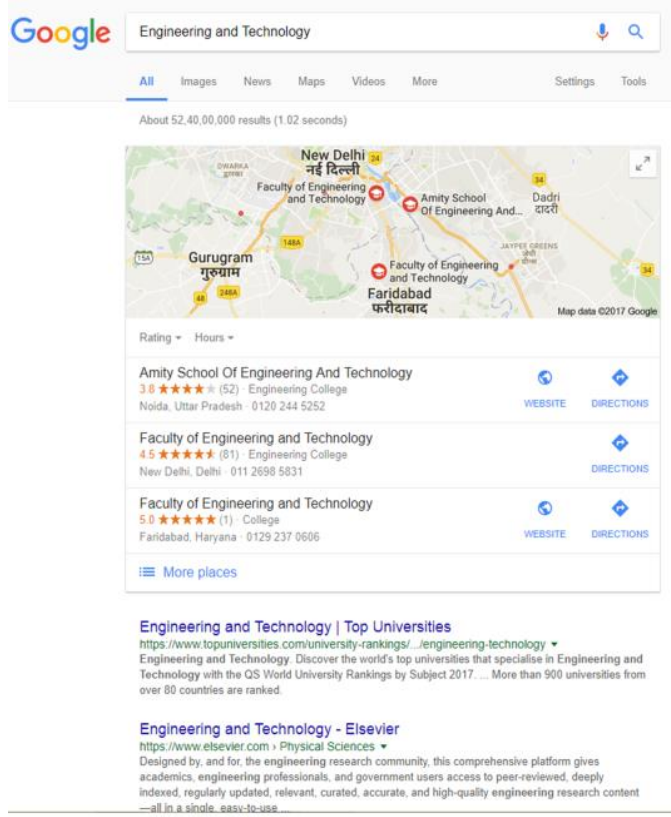

Figure 4: Search results Google vs WolframAlpha 
In the case of Google, the results turn out to be mostly about Engineering and Technology institute around the locality or say top 10 or 20 of them. Note that the word "Top" or "Institutes" were not mentioned in the search. In Wolfram Alpha, the tool considers that the search is a comparison between two different branches of engineering and technology and so it consequently brings organized statistics, important topics, and other useful aspects for comparative analysis. Thereby making it more useful from the educational resource finding point of view. Systems operating in the Web 3.0 standards, in turn, seek contextualized knowledge to assist learners in their jobs, pointing to a series of analysis and potentially helpful information.

Uploading and Integration of the Content

(a) only few min

Content Development is a Continuous Process

(a) 2-3 hrs. a day

For Understanding Bits and Pieces of Google site

- May vary depending on teacher computer skill

(a) 2 hrs. a day

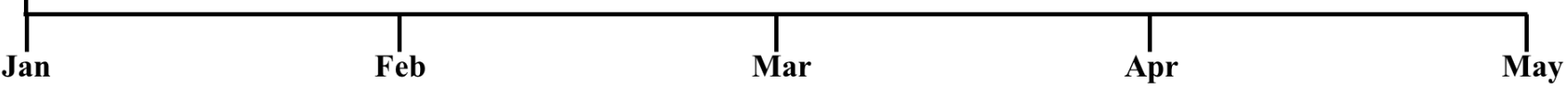

Figure 5: Timeline showing no of hours required to spend to build a digital learning hub over a period of one semester.

After successfully building the digital learning hub we wanted our reader to note that technology integration requires some extra effort from teachers end. Teachers need to allocate time on a weekly basis to educate themselves about technology tools and how they could be used for their learners. A brief outline of the time a teacher required to spend in order to build such a digital learning hub on a semester time scale was plotted in Figure 5. We hope that one-day this small effort can add more incitements that could lead and inspire other educators in their chosen fields to come up with their own digital learning hub.

Before one should start using digital learning hub integrated with all these Web 2.0 tools legal ramifications of publicly disclosing student educational work/information needs to be considered. Learners' consent can be sought to use tools that make their work available to the web. Our submission will be teacher should use only those tools with privacy settings that ask for login.

\section{Conclusions}

All these that we integrated is sounds very ambitious, but question may come is it also working? And if so, is it at per with commercially available LMS. The answer to these questions is a BIG Yes. As this is the only learning management system developed keeping in mind Entrepreneurial Education using freely available online
Web 2.0 and 3.0 tools. In designing the ecosystem of digital learning content for the undergraduate level introductory entrepreneurial course we adopted an approach to integrate only freely available Web 2.0 and 3.0 tools to Google sites. It really had an impact on us and our learner and affected the learning style of our learner. Our findings indicate that this learning ecosystem has proven to be helpful and engaging by the learners. What makes this work more cherished is the fact that using this digital learning hub one can easily achieve teacher-learner, learner-learner, and teacher-teacher communications, interactions and collaborations in one single platform. Moreover, it empowers the learner to navigate their reading, writing, discussion, collaboration, and creation fully on their own. We're in the process of integrating more semantic search tools for easier searching and analytics in a comprehensive way for our entrepreneurial learners'. In conclusion, we must admit, what we have demonstrated through this digital learning hub is just a tip of the integration iceberg that all these Web 2.0 and 3.0 tools offer.

\section{References}

1. K. Oliver, (2010), Integrating Web 2.0 Across the Curriculum, Tech. Trends, 54(2), pp 50-60.

2. L. D. Labbo, K. Place, \& L. Soares, (2010), Fresh perspectives on new literacies and technology integration, Voices from the Middle, 17(3), pp 9-18. 
3. A. L. Harris, \& A. Rea, (2009), Web 2.0 and Virtual World Technologies: A Growing Impact on IS Education, Journal of Information Systems Education, 20(2), pp 137-144.

4. J. Bergmann and A. Sams. (2009), Remixing chemistry class: Two colorado teachers make vodcasts of their lectures to free up class time for hands-on activities, Learning \& Leading with Technology, 36(4), pp 22-27.

5. S. Güzin Mazman and Y. Koçak Usluel., (2010), Modeling educational usage of Facebook, Computers and Education, 55(2) pp 444-453.

6. J. A. Day and J. D. Foley., (2006), Evaluating a Web Lecture Intervention in a Human-Computer Interaction Course, IEEE Transactions on Education, 49(4) pp 420431.

7. L. Aroyo, and D. Dicheva., (2004), The New Challenges for E-learning: The Educational Semantic Web, Educational Technology \& Society, 7(4), pp 59-69.

8. W. Sugar, F. Crawley, and B. Fine., (2004), Examining teachers' decisions to adopt new technology, Educational Technology \& Society. 7(4): pp 201-213.
9. G.-Z. Liu, and G.-J. Hwang., (2010), Identifying learning features and models for contextaware ubiquitous learning with phenomenological research method, British Journal of Education Technology, 41(2), pp E1-E9.

10. T. Lawson, and C. Comber., (1999), Introducing Information and Communication Technologies into Schools: The Blurring of Boundaries, Journal of Information Technology for Teacher Education, 8(1): pp 41-53.

11. V. Ndou, G. Secundo, G. Schiuma and G. Passiante, (2018), Insights for Shaping Entrepreneurship Education: Evidence from the European Entrepreneurship Centers, Sustainability, 10(11): pp 119.

12. O. Zaring, E. Gifford, and M. McKelvey, (2019) doi: 10.1080/03075079.2019.1637841 